\title{
BDNF Regulates Rab11-Mediated Recycling Endosome Dynamics to Induce Dendritic Branching
}

\author{
Oscar M. Lazo, ${ }^{1}$ Andrés Gonzalez, ${ }^{1}$ Maria Ascaño, ${ }^{2}$ Rejji Kuruvilla, ${ }^{2}$ Andrés Couve, ${ }^{3}$ and Francisca C. Bronfman ${ }^{1}$ \\ ${ }^{1}$ Neuronal Cell Biology and Regeneration Laboratory, Millennium Nucleus of Regenerative Biology, Center of Aging and Regeneration, Departamento de \\ Fisiología, Facultad de Ciencias Biológicas, Pontificia Universidad Católica de Chile, Santiago CP 8331010, Chile, ${ }^{2}$ Department of Biology, John Hopkins \\ University, Baltimore, Maryland 21218, and 'Programa de Fisiología y Biofísica, Instituto de Ciencias Biomédicas and Biomedical Neuroscience Institute, \\ Facultad de Medicina, Universidad de Chile, Santiago CP 8380453, Chile
}

Dendritic arborization of neurons is regulated by brain-derived neurotrophic factor (BDNF) together with its receptor, TrkB. Endocytosis is required for dendritic branching and regulates TrkB signaling, but how postendocytic trafficking determines the neuronal response to BDNF is not well understood. The monomeric GTPase Rab11 regulates the dynamics of recycling endosomes and local delivery of receptors to specific dendritic compartments. We investigated whether Rab11-dependent trafficking of TrkB in dendrites regulates BDNF-induced dendritic branching in rat hippocampal neurons. We report that TrkB in dendrites is a cargo for Rab11 endosomes and that both Rab11 and its effector, MyoVb, are required for BDNF/TrkB-induced dendritic branching. In addition, BDNF induces the accumulation of Rab11-positive endosomes and GTP-bound Rab11 in dendrites and the expression of a constitutively active mutant of Rab11 is sufficient to increase dendritic branching by increasing TrkB localization in dendrites and enhancing sensitization to endogenous BDNF. We propose that Rab11-dependent dendritic recycling provides a mechanism to retain TrkB in dendrites and to increase local signaling to regulate arborization.

\section{Introduction}

A well defined extracellular cue inducing dendritic branching is brain-derived neurotrophic factor (BDNF) together with its receptor, TrkB (Yan et al., 1997). BDNF increases branching of cortical and hippocampal neurons in dissociated cultures or in organotypic slices, and mutant mice with inducible deletion of TrkB receptors exhibit a significant reduction of dendritic arborization in cortical neurons (Xu et al., 2000; Horch and Katz, 2002; Cheung et al., 2007; Takemoto-Kimura et al., 2007). In addition, downstream signaling mediators of the BDNF/TrkB pathway are involved in the control of dendritic branching, including the mammalian target of rapamycin kinase and mitogen activated protein kinase signaling pathways (Jaworski et al., 2005; Kumar et al., 2005).

Dendritic branching is also regulated by endocytosis and the intracellular trafficking of organelles. Dendritic trafficking of Rab5-positive early endosomes and Golgi outposts are required

\footnotetext{
Received Sept. 28, 2012; revised Jan. 29, 2013; accepted Feb. 20, 2013.

Author contributions: 0.M.L., A.G., and F.C.B., designed research; 0.M.L. and A.G., performed research; 0.M.L., M.A., R.K., A.C., and F.C.B., contributed unpublished reagents/analytic tools; O.M.L., A.G., and F.C.B., analyzed data; O.M.L., R.K., A.C., and F.C.B., wrote the paper.

This work was supported by FONDECYT (Grants 1085273 and 1120146 to F.C.B.), Millennium Science Initiative (MINREB P07/011-F and CARE-PFB-12/2007 to F.C.B.; P09-015-F to A.C.), the National Institutes of Health (Grant NIH R01 MH080738 and a Whitehall Foundation award to R.K.). We thank Drs. Francis Lee, Rytis Prekeris, Anirvan Ghosh, and Michael Ehlers for sharing the tools detailed in the Materials and Methods section.

The authors declare no competing financial interests.

Correspondence should be addressed to Francisca C. Bronfman, Pontificia Universidad Católica de Chile, Facultad de Ciencias Biológicas, Departamento de Fisiología. Av. Libertador Bernardo 0'Higgins 340, Santiago, CP 8331010 , Chile. E-mail: fbronfman@bio.puc.cl.

DOI:10.1523/JNEUROSCI.4630-12.2013

Copyright $\odot 2013$ the authors $\quad 0270-6474 / 13 / 336112-11 \$ 15.00 / 0$
}

for the development of higher-order branches in Drosophila neurons (Ye et al., 2007; Satoh et al., 2008). It has also been shown that clathrin-mediated endocytosis is required for dendritic branching in Drosophila neurons (Yang et al., 2011). In addition, Rab11-recycling endosomes in dendrites constitute a source of membrane for the growth of dendritic spines and regulate local trafficking of AMPA receptors to the plasma membrane in hippocampal neurons (Kopec and Malinow, 2006; Park et al., 2006). This local phenomenon depends on Myosin Vb, an actin-based motor protein and Rab11 effector that associates with active Rab11 (the GTP-bound form). Both Rab11 and Myosin Vb mediate the recycling of receptors back to the plasma membrane in nonpolarized cells, in the apical surface of epithelial cells, and in the dendrites of polarized hippocampal neurons (Ullrich et al., 1996; Maxfield and McGraw, 2004; Kennedy and Ehlers, 2006; Saraste and Goud, 2007). Endocytosis also regulates the activity of plasma membrane receptors such as the Trks (Bronfman et al., 2007). In fact, internalization of TrkB is required for phosphatidylinositol 3-kinase (PI3K)/Akt signaling and neurite outgrowth of hippocampal neurons (Zheng et al., 2008). Therefore, endocytosis and intracellular trafficking of TrkB receptors appear to be important for dendritic growth and receptor signaling; however, whether Rab11-dependent trafficking of TrkB in dendrites regulates BDNF-induced dendritic branching is not known. We show here that BDNF regulates the dynamics of recycling endosomes by increasing the activity of Rab11 and recruiting Rab11-positive vesicles to dendrites. Consistently, augmented activity of Rab11 led to increased dendritic branching, accumulation of TrkB in dendrites, and increased sensitivity to BDNF. The role of Rab11 in BDNF-dendritic branching is further emphasized by the fact 
that inhibition of Rab11 activity, or the actin-based motor Myo$\sin \mathrm{Vb}$, abolished BDNF-induced dendritic branching. Our findings suggest that Rab11-dependent trafficking of TrkB in dendrites is required for BDNF-induced dendritic branching.

\section{Materials and Methods}

Hippocampal neurons primary culture. Embryonic hippocampal neurons from rats of either sex (embryonic days 17-19) were dissected as described previously (Shimada et al., 1998; Fan et al., 2004) in HBSS. After disaggregation, neurons were resuspended in MEM/HS (Minimum Essential Medium supplemented with 10\% horse serum, 20\% D-glucose, and $0.5 \mathrm{~mm}$ glutamine) and were seeded on poly-L-lysine $(1 \mathrm{mg} / \mathrm{ml})$ at low density for morphometric experiments $\left(7000 \mathrm{cells} / \mathrm{cm}^{2}\right)$ or at medium density for live-cell imaging or biochemical analysis (11,000 cells/ $\mathrm{cm}^{2}$ ). After $4 \mathrm{~h}$, the culture medium was replaced with neurobasal medium supplemented with 2\% B27 and $0.5 \mathrm{~mm}$ glutamine. Proliferation of non-neuronal cells was limited by the use of cytosine arabinoside (AraC; Sigma-Aldrich) at 5 DIV. The animals were obtained from the animal facilities of the Pontificia Universidad Católica de Chile and euthanatized under deep anesthesia according to the bioethical protocols of our institution.

Stimulation and measurement of dendritic arborization induced by $B D N F$. Hippocampal neurons (7 DIV) were stimulated with 4 nм (100 $\mathrm{ng} / \mathrm{ml}$ ) BDNF in culture medium; other treatments such as adenovirus transductions, transfections, and blocking antibody treatments were performed at the same time. In experiments with K252a ( $1 \mu \mathrm{M})$, the drug was added $24 \mathrm{~h}$ after transfection to avoid cell death due to unspecific inhibition of other tyrosine kinases. After $48 \mathrm{~h}$, dendritic arborization was analyzed by Sholl's analysis (Sholl, 1953) and by counting the number of branching points.

For analysis of dendritic branching, the neurons were immunostained with anti-MAP2. We visualized entire dendrites with confocal microscopy using a Zeiss Axiovert 2000 inverted microscope equipped with a laser scan module and Pascal 5 software (Carl Zeiss). Images were acquired using a $63 \times$ objective at $1024 \times 1024$ pixel resolution along the $z$-axis of whole cells. $Z$-stacks were integrated and the images were segmented to obtain binary images. Ten concentric circles with increasing diameters (10 $\mu \mathrm{m}$ each step) were traced around the cell body, and the number of intersections between dendrites and circles was counted and plotted for each diameter. Analysis was performed using the ImageJ plugin developed by the Anirvan Gosh Laboratory (http://biology.ucsd. edu/labs/ghosh/software). The number of total branching points of all dendrites was manually counted from the segmented images.

Live-cell imaging of Rab11. The neurons were transfected with Rab11EGFP using calcium phosphate. After $48 \mathrm{~h}$, they were transferred to Locke's medium for microscopy. Live-cell imaging was performed on an Olympus IX61 microscope equipped with a spinning disk module and a Hamamatsu Orca- $R^{2}$ digital camera connected to a computer with Cell-R software (Olympus). Images of single dendrites were acquired using the $100 \times$ objective at intervals of $20 \mathrm{~s}$ for $30 \mathrm{~min}$ to establish the baseline. The neurons were then stimulated with $4 \mathrm{~nm}(100 \mathrm{ng} / \mathrm{ml})$ BDNF. After allowing 3-5 min for diffusion of the ligand, we started an additional $30 \mathrm{~min}$ of capture. In the experiments using the K252a inhibitor $(1 \mu \mathrm{M})$ or latrunculin $(10 \mu \mathrm{M})$, we preincubated cells for $15 \mathrm{~min}$ with the compound and then established a baseline for $30 \mathrm{~min}$ exactly as described above. Then we stimulated neurons with 4 nM BDNF (100 $\mathrm{ng} / \mathrm{ml}$ ) and, after 3-5 min, started an additional $30 \mathrm{~min}$ of imaging. The analysis of Rab11-EGFP dynamics on dendrites was always performed in the segment immediately distal to the first branching point to avoid interference of the fluorescence changes in the cell body. This segment corresponds to the secondary dendrite. The length of secondary dendrites analyzed was also consistent among treatments. Integrated intensity (intensity of the signal standardized by the area) was measured in the same dendrites before and after the treatments and compared with paired statistical tests (see below).

Analysis of mobility of Rab11-positive endosomes was performed by comparing the distribution of fluorescence in the same dendrite at different time points $(0,5,10,15,20$, and $25 \mathrm{~min})$. To measure the mobility of Rab11-
A

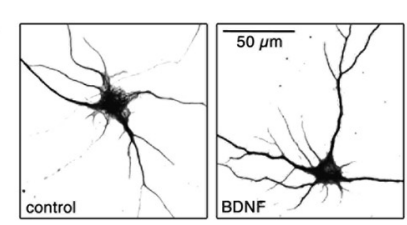

B
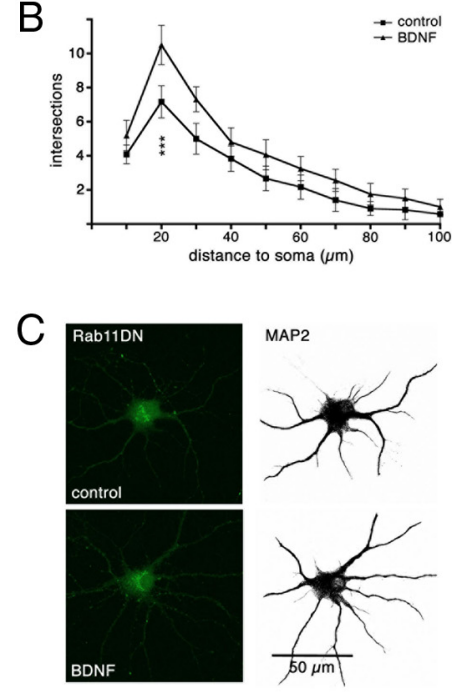

D

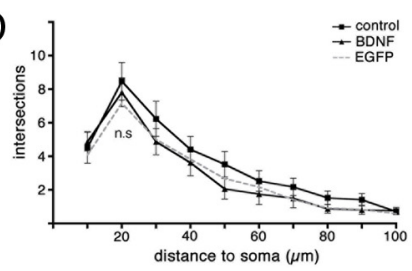

$E$
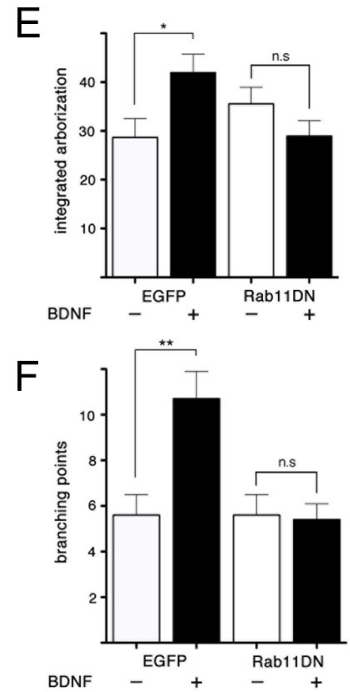

G
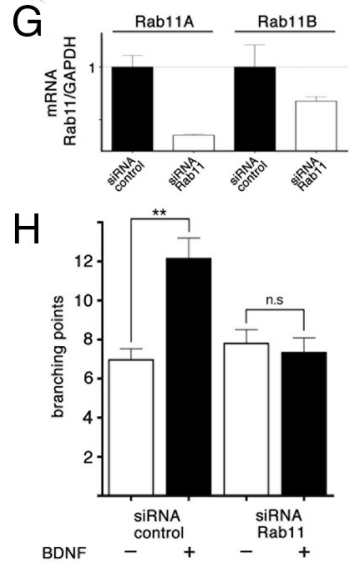

Figure 1. BDNF-induced dendritic branching requires Rab11. A, Hippocampal neurons (7 DIV) were transduced with adenovirus EGFP and stimulated with BDNF for $48 \mathrm{~h}$. After fixation, the neurons were labeled with anti-MAP2 and observed with confocal microscopy. Acquired $z$-stacks were integrated and inverted for morphometric analysis. $B$, Sholl's analysis showed that arborization profiles were significantly higher in EGFP neurons stimulated with BDNF, especially at $20 \mu \mathrm{m}$ from the cell body, suggesting increased branching. $n=24-37$ neurons from three independent experiments. $C$, Hippocampal neurons were transduced with adenovirus Rab11DN (green) and stimulated with BDNF. Neurons were also labeled with anti-MAP2 (black) for morphometric analysis. D, Sholl's analysis showed that neurons expressing Rab11DN did not increase their branching when exposed to BDNF. The profile of control EGFP neurons is plotted with a gray dashed line for reference. $n=21-22$ neurons from three independent experiments. $\boldsymbol{E}, \boldsymbol{F}$, The integrated arborization (area under Sholl's curve shown in $\boldsymbol{E}$ ) and the number of branching points $(\boldsymbol{F})$ were significantly increased by BDNF in neurons expressing EGFP but not in those expressing Rab11DN. G, The requirement of Rab11 for BDNF-induced dendritic branching was confirmed using small interference RNA (siRNA). We used PCR to detect the transcripts of Rab11A and Rab11B and compared their expression with the housekeeping gene GAPDH. We show that Rab11A/B siRNA reduced the abundance of both transcripts compared with the control and when normalized to GAPDH. $\boldsymbol{H}$, Hippocampal neurons transfected with Rab11 siRNA, but not those transfected with control siRNA, failed to show an increase in number of branching points after $48 \mathrm{~h}$ of treatment with BDNF, $n=22-27$ neurons from two independent experiments. ${ }^{*} p<0.01 ;{ }^{* *} p<0.001 ;{ }^{* * *} p<0.0001$

positive organelles, we used the Image Calculator (subtract option) of ImageJ software, which allows subtraction of the fluorescence pixel by pixel of one frame to another one (e.g., fluorescence from frame [ $5 \mathrm{~min}$ after BDNF] - fluorescence from frame [0 min after BDNF] $)$. The fluorescence that is located in the same place will be subtracted, whereas the fluorescence distributed in different places will be conserved. Differences were averaged, standardized, and compared using paired Student's $t$ test.

Analysis of the enlargement of Rab11-positive structures was performed by comparing the fraction of total dendritic Rab11 that is found 
in structures bigger than $0.85 \mu \mathrm{m}^{2}$. Images were segmented and automatic object counting was performed using ImageJ software. Objects were classified by size and the frequency of bigger structures was calculated, averaged, and compared using ANOVA.

Microscopy detection and quantification of active Rab11 in dendrites. A fusion protein of glutathione-S-transferase (GST) and Rab11binding domain with FIP3 was produced in BL21 E. coli, transformed with pGEX-GSTFIP3 plasmid (generously provided by Dr. Rytis Prekeris), and stimulated for $4 \mathrm{~h}$ with IPTG. The protein GST-FIP3 was purified from bacteria lysate using glutathione-agarose beads. For use as a probe, the protein was eluted in a solution of reduced glutathione (similar methods have been described previously for other GTPases such as RhoA; Gehler et al., 2004).

The neurons were stimulated with $4 \mathrm{nM}$ BDNF (100 ng/ml) for $20 \mathrm{~min}$, fixed with PFA, permeabilized, and blocked in 3\% BSA in incubation buffer ( $50 \mathrm{~mm}$ Tris-Cl, $50 \mathrm{~mm} \mathrm{NaCl}, 5$ mu $\mathrm{MgCl}^{2}, 0.5$ mm DTT, 1 mm EDTA, $0.25 \mathrm{M}$ sucrose, and $0.2 \%$ Triton X-100, pH 7.2) for 45 $\mathrm{min}$. The neurons were then incubated overnight with $\sim 20 \mu \mathrm{g} / \mathrm{ml}$ GST-FIP3 in incubation buffer with rotation at $4^{\circ} \mathrm{C}$. After 2 brief washes in HBSS, the neurons were refixed in PFA and washed in PBS and then a standard immunofluorescence assay with anti-GST was performed.

We performed microscopy of single dendrites from neurons labeled with GST-FIP3. We analyzed the three brightest secondary dendrites for each neuron and measured the integrated intensity (intensity of the signal standardized by the area). The background was calculated from images of neurons treated with GST and this baseline was calculated for and subtracted from each dataset.

Immunoendocytosis and colocalization. For the colocalization studies, the neurons were cotransfected with EGFP and Flag-tagged TrkB using calcium phosphate (Watson and Latchman, 1996; Goetze et al., 2004) or Lipofectamine 2000 (Invitrogen). After $48 \mathrm{~h}$, the neurons were incubated for $90 \mathrm{~min}$ in neurobasal medium for depletion of endogenous trophic factors and loaded with Alexa Fluor 647-conjugated transferrin for $60 \mathrm{~min}$ to label recycling endosomes. Neurons were then washed briefly in chilled PBS and incubated with mouse anti-Flag antibodies conjugated to Alexa Fluor 555 fluorochrome $(20 \mu \mathrm{g} / \mathrm{ml})$. After $30 \mathrm{~min}$, the cells were washed with PBS at $37^{\circ} \mathrm{C}$ and stimulated with $4 \mathrm{~nm} \mathrm{BDNF}(100 \mathrm{ng} / \mathrm{ml})$ for $15 \mathrm{~min}$, fixed, and compared with no-internalization controls.

Dendrite images were acquired using confocal microscopy, treated with deconvolution algorithms, and then colocalization of TrkB or transferrin with Rab11 was analyzed by calculating the Manders correlation index (M1; Bolte and Cordelieres, 2006). We estimated the resolution limit of our correlation analysis by studying colocalization in control dendrites that were fixed, not permeabilized, and stained with anti-Flag antibody. The limit was calculated to be $\mathrm{M} 1=0.194$. In addition, to identify true colocalization events, we performed Van Steensel's analysis and tested the results for Gaussian fitting (all of our samples fit with an $R^{2} \geq 0.9$ ). Analysis was performed using the JACoP plugin for ImageJ (http://rsbweb.nih.gov/ij/plugins/track/jacop.html).

For recycling analysis, the neurons were cotransfected with EGFP and/or Rab11DN and Flag-tagged TrkB. After $48 \mathrm{~h}$, the neurons were incubated for $90 \mathrm{~min}$ in neurobasal medium for depletion of endogenous trophic factors. The neurons were then washed briefly in chilled PBS and incubated with mouse anti-Flag antibodies conjugated to Alexa Fluor 555 fluorochrome $(20 \mu \mathrm{g} / \mathrm{ml})$. After $30 \mathrm{~min}$, the cells were washed with
PBS at $37^{\circ} \mathrm{C}$ and stimulated with $4 \mathrm{~nm} \mathrm{BDNF}(100 \mathrm{ng} / \mathrm{ml})$ for $30 \mathrm{~min}$. After the internalization of TrkB-Flag receptors, the remaining antibodies on the cell surface were removed using three washes with PBS/EDTA. Recycled receptors back on the cell surface were labeled using a $60 \mathrm{~min}$ incubation with Alexa Fluor 647-conjugated secondary anti-mouse antibodies. Recycling is proportional to the detected anti-Flag signal that returned to the plasma membrane minus the nonspecific binding of the antibody to the neurons at the initial "zero" time of recycling. The neurons were finally washed and fixed in PFA/sucrose and images were captured by confocal microscopy.

Determination of dendritic levels of endogenous TrkB. The same neurons used for morphologic studies were colabeled with anti-TrkB for analyzing the amount of the endogenous receptor in dendrites. Images of equivalent segments of secondary dendrites were acquired as $z$-stacks in confocal microscopy and reconstructed. The integrated fluorescence in dendrites was then measured as described above for the other markers.

TrkB/BDNF sensitization experiment. Hippocampal neurons (7 DIV) were transduced with adenovirus for the expression of either control EGFP or the Rab11CA mutant. After $48 \mathrm{~h}$, the neurons were stimulated with $0.02,0.2$, or $2 \mathrm{~nm} \mathrm{BDNF}(0.5,5$, and $50 \mathrm{ng} / \mathrm{ml}$, respectively) for 15 $\mathrm{min}$. After washing, the neurons were fixed in 4\% PFA, 3\% sucrose, and phosphatase inhibitors. We then performed an immunofluorescence assay to detect phosphorylated CREB (pCREB anti-ser133) in the cell nucleus. Nuclei were labeled with Hoechst stain for $20 \mathrm{~min}$ and the staining defined the region for measurement of integrated fluorescence (intensity of the signal per area units). The values are expressed as nuclear pCREB/ whole cell pCREB ratio and standardized to the control (time 0 ). 
A

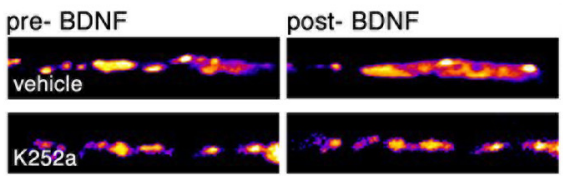

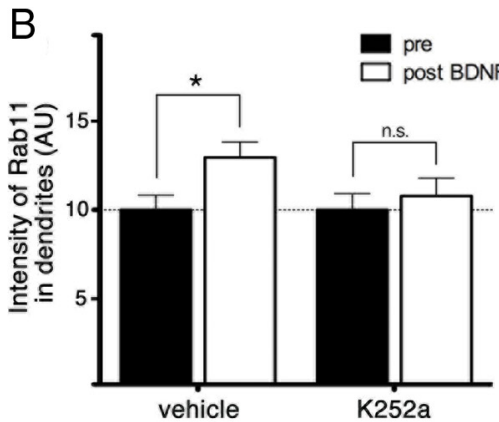

Figure 3. BDNF-induced increase of Rab11 localization in dendrites depends on TrkB activity. A, BDNF-induced increase of Rab11 in dendrites was studied with the same method described in Figure 2 in the presence of the tyrosine kinase inhibitor K252a. Representative images of the same dendrites before and after BDNF are shown with a pseudocolor intensity indicator. $\boldsymbol{B}$, Plot of quantification of mean intensity in the same dendrites before and after BDNF stimulation. Values with or without BDNF correspond to six independent experiments and were compared using paired $t$ test. ${ }^{*} p<0.01$.

A
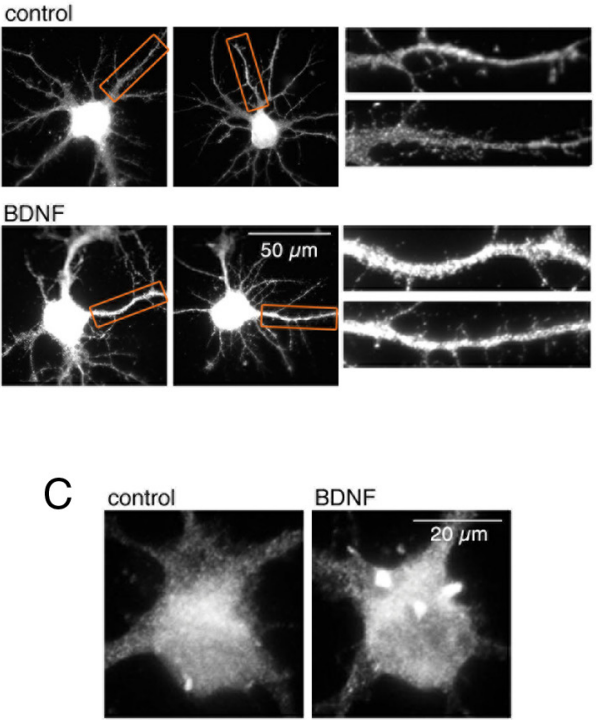
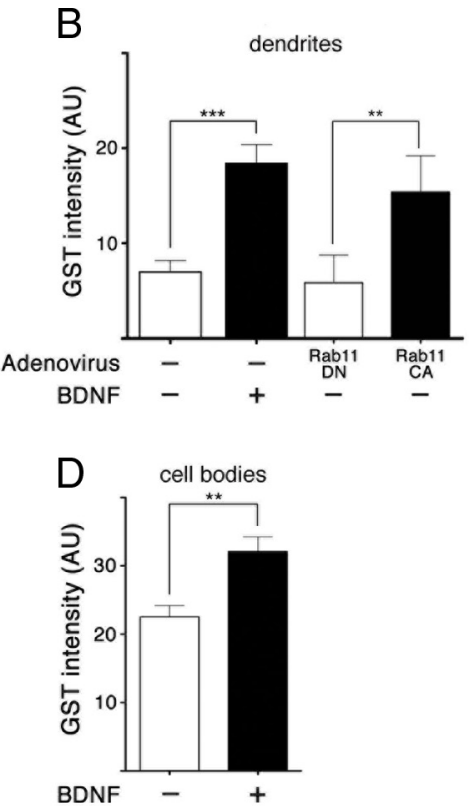

Figure 4. BDNF signaling increases Rab11-GTP in neurons. A, Hippocampal neurons were stimulated with BDNF or vehicle (control) for 20 min, fixed, and probed for GTP-bound Rab11 with a GST-FIP3 fusion protein. GST was developed for immunofluorescence using anti-GST antibodies followed by fluorescently conjugated secondary antibodies. Insets correspond to the brightest dendrite of each neuron and are indicated with an orange rectangle. $\boldsymbol{B}$, We quantified intensity of the three brightest dendrites per neuron and observed that BDNF increased GTP-bound Rab11 in dendrites significantly. $n=182-191$ dendrites from 61-64 neurons in five different experiments. We also performed the experiment in neurons (with no BDNF stimulation) expressing Rab11DN and Rab11CA as negative and positive controls, respectively. ${ }^{* *} p<0.0001 . C, D$, In the same experiments, we analyzed images from the cell bodies separately. We found that the basal activation of Rab11 was high, but BDNF also increased GTP-bound Rab11 significantly. $n=54-72$ neurons from two independent experiments. ${ }^{* *} p<0.005$.

Immunofluorescence. Hippocampal neurons were washed in PBS and then fixed with ice-cold 3\% PFA and 4\% sucrose in PBS for 15 min. After 3 washes, the cells were incubated in $0.15 \mathrm{~m}$ glycine, $\mathrm{pH} 7.4$, for $10 \mathrm{~min}$. The neurons were washed and then blocked and permeabilized with $3 \%$ BSA and $0.2 \%$ saponin in PBS for $1 \mathrm{~h}$. The samples were then incubated overnight at $4^{\circ} \mathrm{C}$ with the following primary antibodies: mouse antiMAP2 (Millipore), rabbit anti-TrkB (Millipore, Millipore), rabbit antiGST (Abcam), rabbit anti-Myosin Vb (kindly provided by Dr. El-Husseini, British Columbia University) at a dilution of 1:200 in 3\% BSA, $0.05 \%$ saponin, $0.1 \mathrm{~mm} \mathrm{CaCl}_{2}$, and $1.5 \mathrm{~mm} \mathrm{MgCl}_{2}$ in PBS. After 3 washes, the cells were incubated with fluorescently conjugated secondary antibodies at 1:500 in the same solution for $1.5 \mathrm{~h}$ at room temperature. For the assay of nuclear pCREB detection, neurons were blocked and permeabilized in $4 \%$ BSA and $0.5 \%$ Triton X-100 and then incubated with rabbit anti-pCREB (Cell Signaling Technology) at a dilution of 1:750 in 2\% BSA, $0.1 \%$ Triton X-100, $0.1 \mathrm{~mm} \mathrm{CaCl}_{2}$, and $1.5 \mathrm{~mm}$ $\mathrm{MgCl}_{2}$ in PBS. Secondary antibodies were diluted in the same incubating solution. Finally, the samples were washed in PBS and distilled water and mounted in Mowiol for fluorescence microscopy.

Statistical analysis. Sholl's analysis curves and intensity profiles in live-cell imaging experiments were compared using a two-way ANOVA of repeated measures, followed by a Bonferroni posttest to compare all pairs of datasets. Averaged measures of fluorescence in live-cell imaging were compared by paired Student's $t$ test. Groups of treatments (integrated arborization, branching points, intensity of TrkB fluorescence) were compared using a one-way ANOVA or Tukey's test, followed by Dunn's comparison of all columns; only the sensitization assay was compared using a twoway ANOVA test. The intensity of GST-FIP3 labeling was compared using Student's $t$ tests. Significance levels ( $p<0.01, p<0.001$, or $p<$ $0,0001)$ and the sample size ( $n$, the number of sample units and times the experiment was repeated) are indicated in each figure legend. The values are means \pm SEM. Statistical analyses were performed using Prism 4 for Macintosh (GraphPad).

\section{Results}

\section{BDNF-induced dendritic branching} requires Rab11

It is well known that BDNF causes dendritic growth in hippocampal neurons (Horch and Katz, 2002; Cheung et al., 2007; Takemoto-Kimura et al., 2007). We conducted a series of complementary experiments to investigate whether BDNFinduced dendritic growth requires intracellular trafficking along the slow recycling route. First, we performed a standard BDNF-dependent dendritic growth assay by incubating 7 DIV hippocampal neurons grown at low density with $4 \mathrm{~nm}$ BDNF (100 ng/ml) for $48 \mathrm{~h}$. As expected, we found that BDNF increased dendritic arborization (Fig. $1 A, B, E$; control $28.7 \pm$ 6.3, BDNF 41.9 \pm 7.5$)$. Sholl's profiles indicated significant differences in arborization at $20 \mu \mathrm{m}$ from the center of the cell body, indicating that exogenous addition of BDNF affected mainly the branching of dendrites and not the number of primary dendrites or total dendrite length (Fig. 1B). We measured the number of branching points directly (Fig. $1 F$ ) and found that BDNF induced a twofold increase in the ramification of dendrites. We then performed the same assay in 7 DIV hippocampal neurons transduced with adenovirus driving the expression of EGFP and a dominant-negative mutant of Rab11 (Rab11DN). We found that expression of Rab11DN completely abolished BDNF-dependent dendritic growth (Fig. $1 C, D, F$ ). To confirm that Rab11 activity was required for BDNF-induced dendritic branching and that the effect was not due to nonspecific effects of the Rab11DN mutant, we transfected hippocampal 
A

vehicle

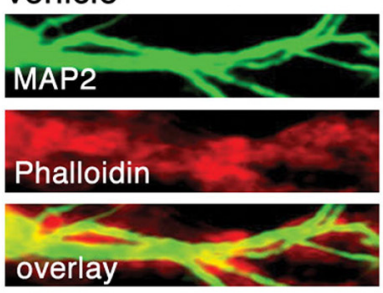

B

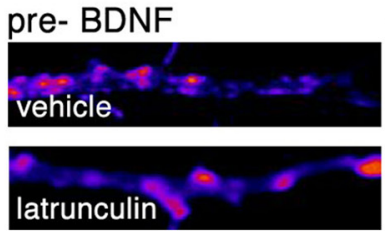

C

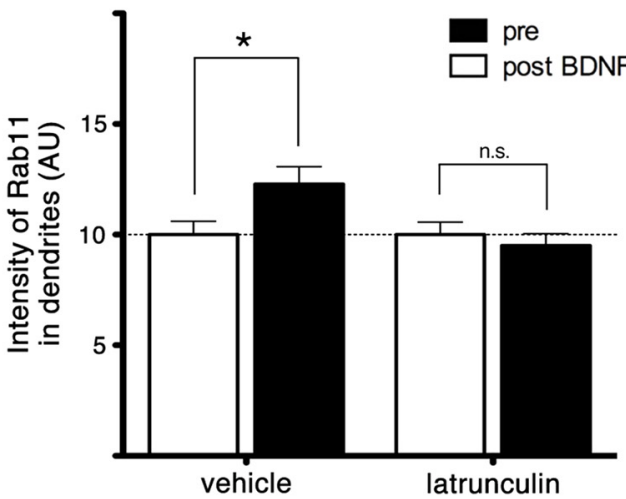

Figure 5. BDNF-induced increase of Rab11 localization in dendrites depends on the actin cytoskeleton. $\boldsymbol{A}$, To analyze whether the BDNF-induced increase of Rab11 in dendrites depends on trafficking through actin-based molecular motors, we incubated neurons with the actin destabilizer latrunculin for $15 \mathrm{~min}$. Treated and control dendrites were colabeled for MAP2 and phalloidin. Labeling for F-actin was reduced significantly in treated neurons. $\boldsymbol{B}, \mathrm{BDNF}$-induced increase of Rab11 in dendrites was studied with the same method described in Figure 2 but in the presence of $10 \mu \mathrm{m}$ latrunculin. Representative images of the same dendrites before and after BDNF are shown with a pseudocolor intensity indicator. C, Quantification of live-cell imaging experiments investigating Rab11EGFP mobilization to dendrites (Fig. 2) showed that latrunculin inhibited BDNF-induced recruitment of Rab11 to dendrites. $n=4$ latrunculin and 10 control independent experiments. ${ }^{*} p<0.01$.

neurons with a small interference RNA directed against the sequence of Rab11A and Rab11B. The transfection of the antisense oligonucleotides consistently reduced the number of transcripts from both Rab11A and Rab11B, both as measured by PCR and compared with the housekeeping gene GAPDH (Fig. 1G). Neurons transfected with control oligonucleotides and treated with BDNF increased dendritic branching points, as shown for naive neurons; however, neurons transfected with the small interference RNA for Rab11A/B did not respond to BDNF (Fig. $1 H$ ).

\section{BDNF induces accumulation of Rab11-positive endosomes} in dendrites

To determine whether stimulation with BDNF results in a change of distribution of Rab11-positive vesicles, 7 DIV hippocampal neurons were transfected with a plasmid driving the expression of Rab11-EGFP. After 48 h, we performed live-cell imaging of the Rab11-positive structures in secondary dendrites. We first established a baseline by capturing images of Rab11 in a single dendrite for $45 \mathrm{~min}$ and then stimulated the neurons with $4 \mathrm{~nm} \mathrm{BDNF}$ and captured images of the same dendrite for an additional $45 \mathrm{~min}$
A
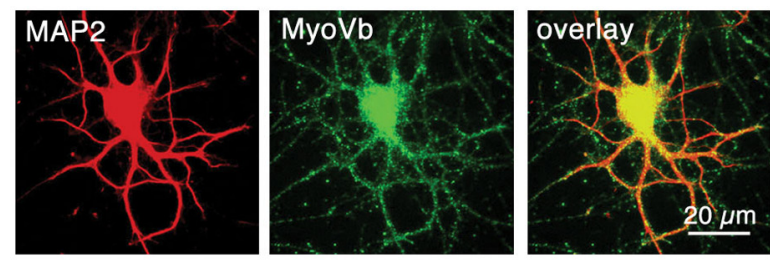

B
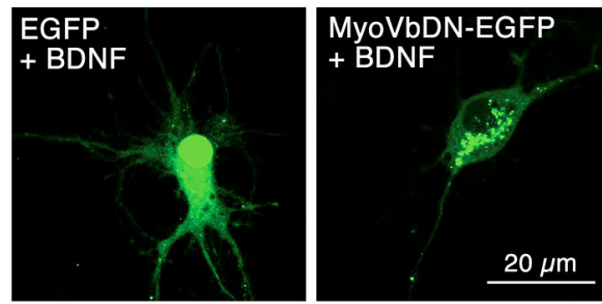

C

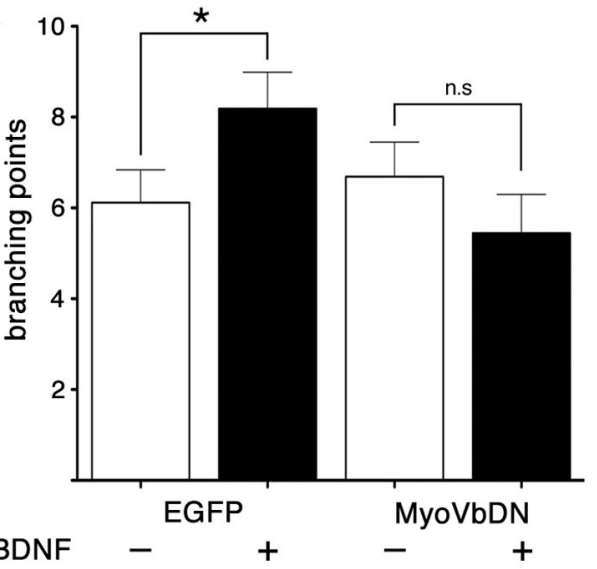

Figure 6. The actin-dependent molecular motor Myosin $\mathrm{Vb}$ is expressed in hippocampa neurons and is required for BDNF-induced dendritic arborization. $\boldsymbol{A}$, Hippocampal neurons at 7 DIV were probed for Myosin Vb (green), an actin-based molecular motor that binds to the active form of Rab11. Costaining with anti-MAP2 (red) shows that Myosin Vb was distributed along the entire somatodendritic domain. $\boldsymbol{B}$, To evaluate the participation of Myosin Vb in BDNFinduced dendritic branching, we transfected hippocampal neurons with EGFP or a dominantnegative mutant of Myosin $\mathrm{Vb}$ that was EGFP tagged (MyoVbDN). We then stimulated the neurons for $48 \mathrm{~h}$ with BDNF and analyzed its dendritic arborization. C, Quantification of dendritic branching points revealed that BDNF-induced arborization was blocked significantly in MyoVbDN-expressing neurons compared with neurons expressing EGFP. $n=16-18$ neurons from three independent experiments. ${ }^{*} p<0.01$.

(Fig. 2A). When we analyzed the total intensity of Rab11WTEGFP in the visualized dendritic segments, we observed that the intensity increased significantly after the addition of BDNF (Fig. $2 B$ ); this effect was dependent on the phosphorylation of receptors because it was blocked by the presence of a K252a inhibitor (Fig. 3). We also observed that after the addition of BDNF, Rab11-positive structures were 20\% less mobile (Fig. 2C,D) and significantly larger (Fig. 2E,F), suggesting that there is not only an increase in the amount of the protein, but also an increase of Rab11-positive vesicular compartments in dendrites after stimulation with BDNF.

\section{BDNF increases the amount of active Rab11 in dendrites}

To assess whether the increased accumulation of Rab11-positive endosomes in BDNF-induced dendrites is accompanied by BDNF-induced activation of Rab11, we measured the proportion of active Rab11 (GTP-bound conformation) after BDNF treatment. We treated 9 DIV hippocampal neurons with BDNF and measured the activity of Rab11 in situ using a standard assay that 
A
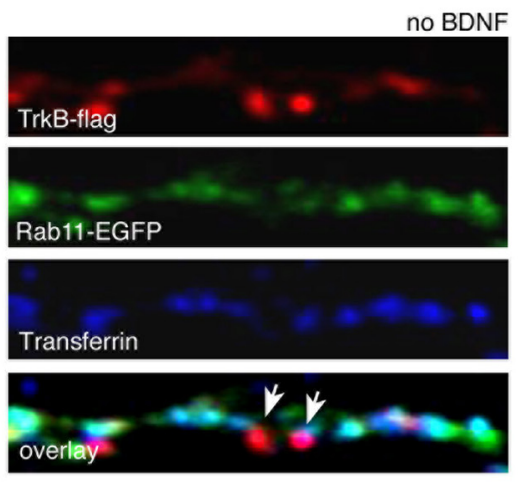

C

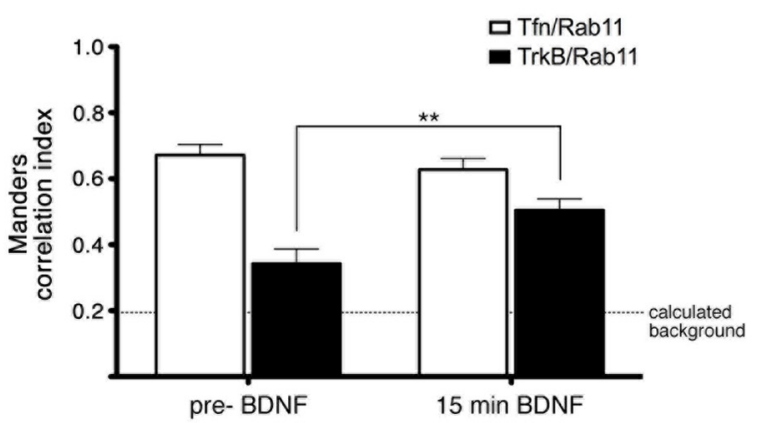

$\mathrm{D}$
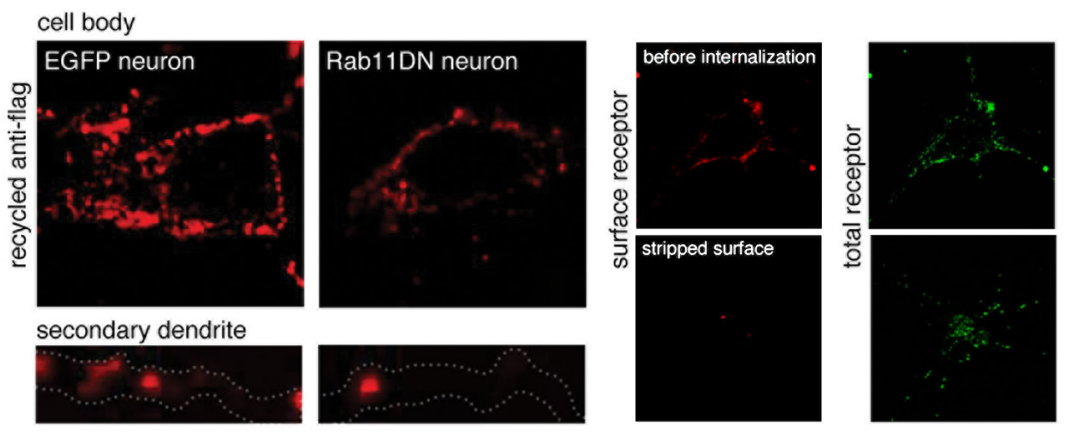

$E$
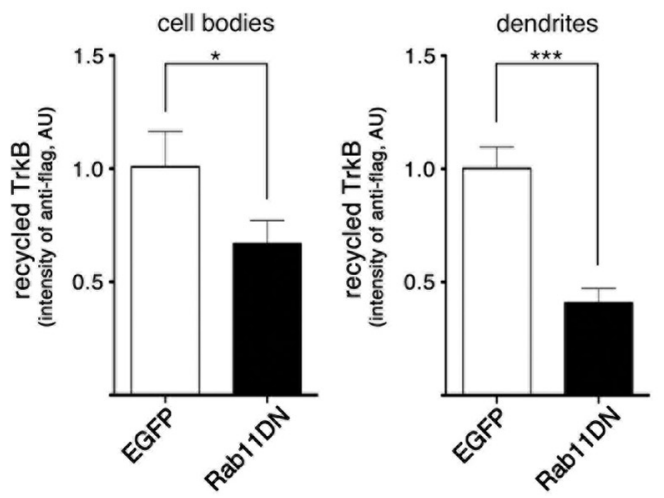

Figure 7. Endocytosed TrkB receptor recycles through Rab11-positive endosomes in the cell body and dendrites. $A, B$, Hippocampal neurons were cotransfected with TrkB-Flag and Rab11-EGFP. After $48 \mathrm{~h}$, the neurons were loaded with transferrin as a recycling endosome marker and then incubated at $4^{\circ} \mathrm{C}$ with anti-Flag antibody. TrkB internalization was stimulated with BDNF at $37^{\circ} \mathrm{C}$. Fixed neurons were observed with confocal microscopy. Without $\operatorname{BDNF}(\boldsymbol{A})$, anti-Flag was located at the surface of dendrites, whereas Rab11 and transferrin colocalized within the dendrites. After $15 \mathrm{~min}$ of BDNF stimulation (B), TrkB receptors had an intracellular distribution that partially colocalized with Rab11 and transferrin. C, Quantification of colocalizing Transferrin/Rab11 and TrkB/Rab11 using Manders correlation index (M1) before and after internalization of TrkB with BDNF. Although preloaded transferrin was always correlated $>0.6$ with Rab11, TrkB exhibited an initial Manders index of 0.343 , which increased significantly after 15 min with BDNF, reaching 0.505. Background correlation has been calculated from fixed - and not permeabilizeddendrites stained with anti-Flag and is indicated in the figure, representing the resolution limit of our colocalization analysis ( 0.194). This result suggests that, after internalization, part of the TrkB receptors were targeted to Rab11 endosomes. uses a fusion protein of glutathione-Stransferase (GST) and the Rab11-binding domain of FIP3, a known effector of this GTPase (Hales et al., 2001; Meyers and Prekeris, 2002). After BDNF treatment, fixed neurons were incubated with GSTFIP3. We then detected the probe via immunofluorescence using anti-GST antibodies. In dendrites, Rab11-GTP increased $175 \%$ after stimulation with BDNF compared with the control condition (Fig. $4 A, B$ ). As negative and positive controls for this experiment, we used hippocampal neurons transduced with a Rab11 dominant-negative (Rab11DN) or a Rab11 constitutively active (Rab11CA) mutant, respectively. Neurons expressing Rab11DN displayed significantly lower GST-FIP3 labeling compared with neurons expressing Rab11CA. Finally, we studied Rab11 activity in the cell bodies and found that stimulation with BDNF caused a $42 \%$ increase in GST-FIP3 labeling (Fig. 4C,D). These data indicate that BDNF induces an increase in the GTPbound form of Rab11, enhancing its ability to interact with effector proteins, a phenomenon that appears to be more robust in dendrites than in cell bodies.

BDNF-mediated dendritic branching is dependent on Myosin Vb activity Several reports have shown that Rab11dependent recycling and movement of vesicles in dendrites depends on Myosin $\mathrm{Vb}$ and actin microfilaments (Lapierre et al., 2001; Hales et al., 2002; Lisé et al., 2006; Wang et al., 2008; Chu et al., 2009). First, to analyze whether the BDNFdependent increase of Rab11 in dendrites requires the actin cytoskeleton, we desta-

$\leftarrow$

$n=17-25$ dendrites from three independent experiments. ${ }^{* *} p<0.001$. D, To analyze whether the recycling of TrkB receptors depends on Rab11 endosomes, we cotransfected EGFP or Rab11DN and TrkB-Flag in hippocampal neurons. We first labeled the TrkB-Flag at the cell surface with mouse anti-Flag and then stimulated internalization of TrkB with BDNF and washed the remaining anti-Flag in the plasma membrane. We incubated the neurons with a fluorescently labeled secondary antibody to detect the recycling receptors that returned to the cell surface. Images from cell bodies and secondary dendrites were acquired by confocal microscopy. Right, Surface and total TrkB-Flag receptor for two controls: first, before the internalization when all the labeled receptor was in the cell surface and, second, after the PBS-EDTA stripping, when there was internalized receptor but no labeled receptor in the surface. $\boldsymbol{E}$, Quantification of fluorescence intensity showed that the expression of Rab11DN decreased the recycling of TrkB receptors in the cell body and secondary dendrites significantly compared with the EGFP-expressing neurons. $n=18-33$ cell bodies and 40-62 dendrites from three independent experiments. ${ }^{*} p<0.01$; ${ }^{* * *} p<0.0001$. 
bilized the actin filaments with $10 \mu \mathrm{M}$ latrunculin for $15 \mathrm{~min}$ (Fig. 5A). Destabilization of polymerized actin blocked the BDNF-induced increase of Rab11 fluorescence in dendrites (Fig. $5 B, C)$, suggesting that actin-associated molecular motors are involved in the movement of Rab11-positive structures along the dendrites and are required for the accumulation of Rab11-vesicles in dendrites. Therefore, we then investigated whether Myosin $\mathrm{Vb}$ is a downstream effector of active Rab11 in regulating BDNF-induced dendritic branching. As expected, Myosin Vb was expressed and distributed in the somatodendritic domains (Fig. 6A). We transfected 7 DIV hippocampal neurons with a dominantnegative mutant of Myosin $\mathrm{Vb}$ EGFP (MyoVbDN) or with EGFP and stimulated the neurons with BDNF for $48 \mathrm{~h}$. Consistent with our hypothesis, we found that BDNF failed to induce an increase of dendritic branching points in MyoVbDN-expressing neurons compared with control neurons (Fig. $6 B, C$ ).

These results suggest that BDNF induces the accumulation of Rab11-positive endosomes into dendrites by a mechanism that involves the actin cytoskeleton and the actin-binding motor Myosin $\mathrm{Vb}$. MyoVb-dependent trafficking of Rab11 vesicles is required downstream of $\mathrm{BDNF} /$ TrkB signaling to induce dendritic branching, because expression of $\mathrm{My}$ oVbDN prevents BDNF-induced dendritic branching.

\section{TrkB is a cargo for Rab11 endosomes}

In peripheral sympathetic neurons, the anterograde transport of TrkA receptor to axons is mediated via Rab11-positive endosomes (Ascaño et al., 2009). Given that we observed an increase in Rab11-positive endosomes in dendrites with BDNF stimulation, we investigated whether the BDNF receptor TrkB was a cargo of Rab11-positive endosomes. Using an immunoendocytosis assay, we found that after the addition of BDNF, there was a $50.5 \%$ of colocalization between internalized Flag-tagged TrkB receptors and Rab11EGFP vesicles in dendrites (Manders correlation index M1 between TrkB/Rab11 was 0.343 with no BDNF and reaches $0.505 \pm 0.036$ after BDNF stimulation; Fig. $7 A-C)$. Moreover, expression of Rab11DN reduced the recycling of Flagtagged TrkB receptors in the cell body and in dendrites (Fig. $7 D, E)$. The inhibitory effect of Rab11DN on the recycling of Flag-tagged TrkB in dendrites was more pronounced than in neuronal cell bodies (Fig. $7 D, E$ ), which supports the idea that Rab11 endosomes were being accumulated in dendrites.

\section{Expression of a constitutively active form of Rab11 increases} TrkB localization in dendrites, dendritic branching, and responsiveness to $\mathrm{BDNF}$

To determine whether activation of Rab11 was sufficient to increase dendritic branching or if it has a synergistic effect with BDNF, we compared the BDNF-induced arborization in neurons transduced with adenoviruses for Rab11CA and EGFP. Interest-
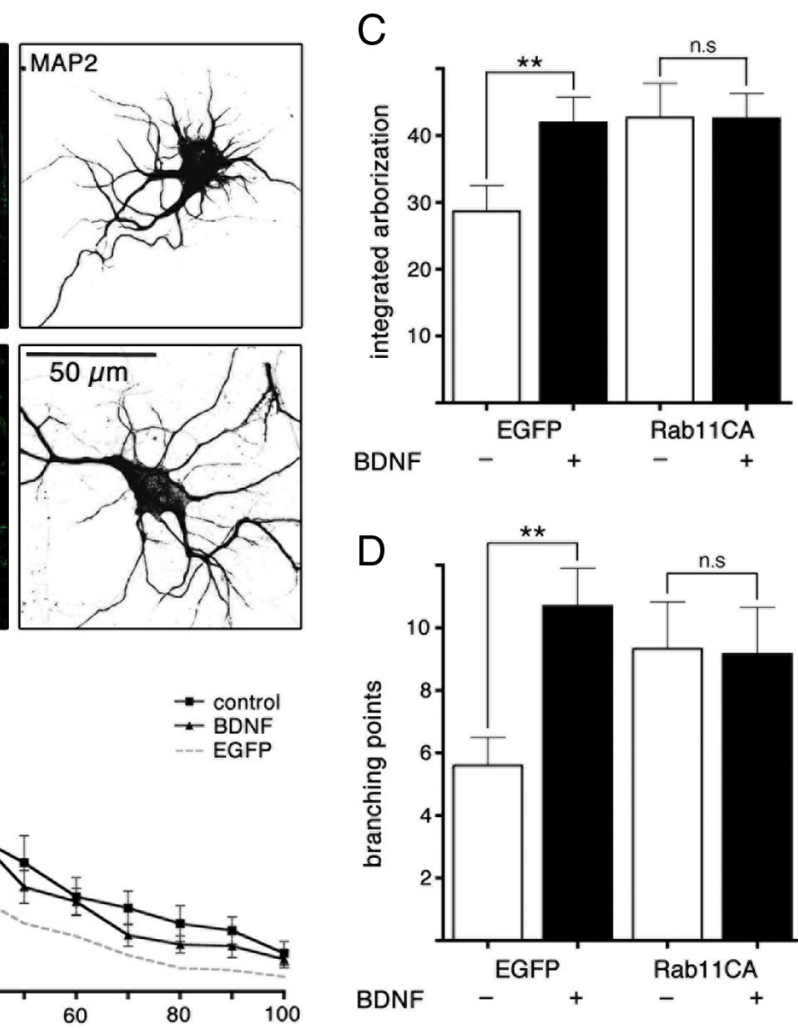

distance to soma $(\mu \mathrm{m})$

Figure 8. Expression of Rab11CA increases dendritic branching independently of exogenous stimulation with BDNF. A, Hipocampal neurons were transduced with adenovirus Rab11CA and stimulated with $4 \mathrm{~nm} \mathrm{BDNF}(100 \mathrm{ng} / \mathrm{ml})$ for $48 \mathrm{~h}$. Transduced area $(\boldsymbol{C})$, as well as the number of branching points $(\boldsymbol{D})$, showed that neurons expressing Rab11CA increased arborization even if they were not stimulated with exogenous BDNF. $n=23-26$ neurons from four independent experiments. ${ }^{* *} p<0.001$.

ingly, we found that the expression of Rab11CA increased arborization, even in neurons without any exogenous BDNF stimulation. Moreover, Rab11CA neurons did not exhibit additional increases in dendritic arborization compared with EGFP neurons when treated with exogenous BDNF (Fig. 8A-C). Similar results were obtained when branching points were quantified (Fig. 8D).

Given that TrkB recycling in dendrites depends on Rab11 and that BDNF activation induces the movement of Rab11 endosomes to dendrites, we hypothesized that the expression of Rab11CA would increase TrkB levels in dendrites and may thus increase neuronal sensitivity to endogenous BDNF that was previously under its sensitivity threshold. This may explain why Rab11CA expression is sufficient to increase dendritic branching without the addition of BDNF to the cell culture media. When we transduced 9 DIV hippocampal neurons with EGFP and Rab11CA for $48 \mathrm{~h}$ and then used immunostaining to analyze the endogenous distribution of TrkB in dendrites, we observed that neurons expressing the Rab11CA form exhibited more TrkB in the dendritic shaft. We also observed that the Rab11CA-induced increase of endogenous dendritic TrkB was not abolished by the presence of the tyrosine kinase inhibitor K252a, suggesting that accumulation of $\operatorname{TrkB}$ in dendrites is downstream of increased Rab11 activity (Fig. 9A,B).

To address the possibility that Rab11CA expression sensitizes neurons to endogenously secreted BDNF, we analyzed Rab11CAinduced dendritic branching in the presence of an antibody that blocks the binding of BDNF to TrkB or in the presence of the 
A
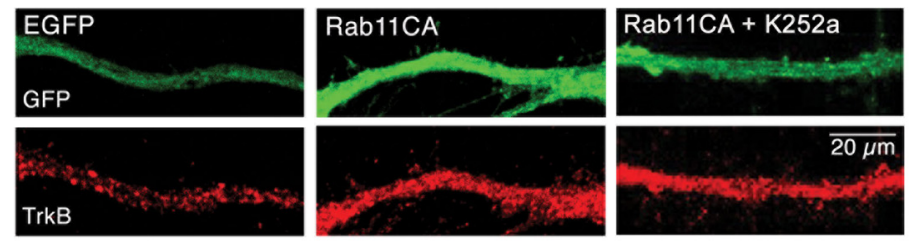

B

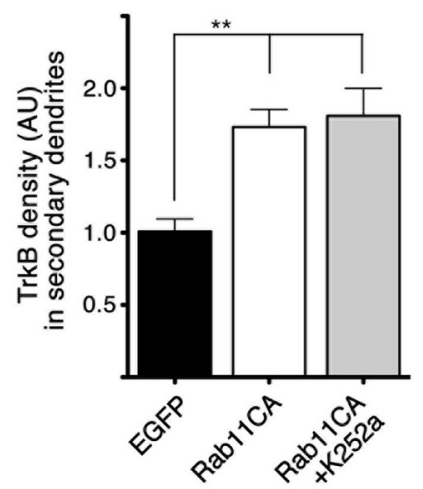

D
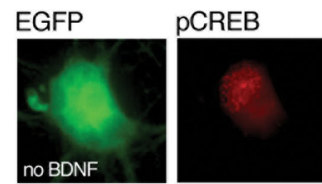
overlay

\section{C}
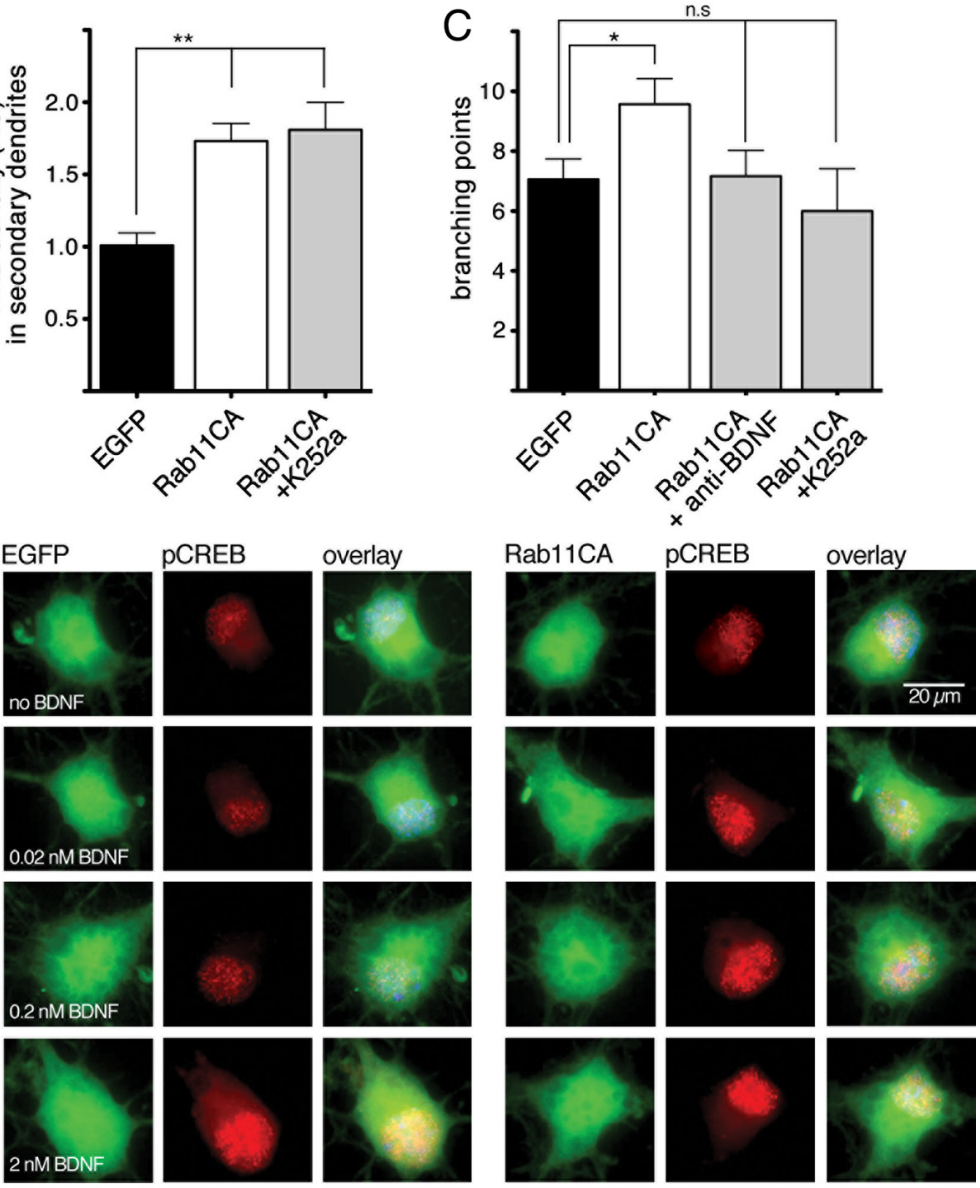

E

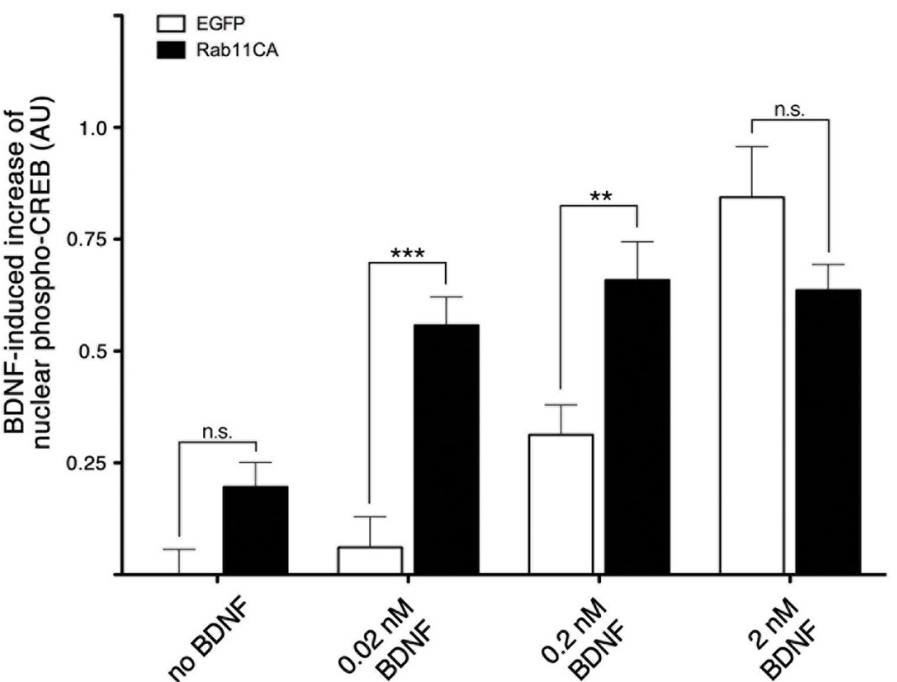

Figure 9. Expression of Rab11CA induces an increase of TrkB localization in dendrites and sensitization to BDNF.A, Hippocampal neurons were transduced with adenovirus EGFP or Rab11CA (green) and after $24 \mathrm{~h}$ a group of Rab11CA-expressing neurons was treated with K252a $1 \mu \mathrm{m}$. After $48 \mathrm{~h}$, the neurons were fixed and labeled with anti-TrkB (red). Rab11CA and Rab11CA + K252a showed increased localization of TrkB in dendritic protrusions. $B$, The intensity of TrkB labeling was measured in secondary dendrites, showing that TrkB was enriched in dendrites of Rab11CA-expressing neurons regardless of whether they were treated with K252a. $n=$ dendrites from $18-24$ neurons from two different experiments. ${ }^{*} p<0.01$. C, To determine whether the increase inhibitor K252a. We found that both depletion of endogenously secreted BDNF and inhibition of tyrosine kinase activity of the receptor completely abolished the Rab11CA-induced increase of dendritic branching points (Fig. 9C). Finally, consistent with the idea that expression of Rab11CA sensitizes neurons to endogenous BDNF, we found higher levels of pCREB, a transcription factor activated by TrkB signaling, in Rab11CA-expressing hippocampal neurons compared with EGFP-expressing neurons at low doses of BDNF (0.02 nM and 0.2 nM). However, at higher doses of BDNF beyond saturating levels $(2 \mathrm{~nm})$, the difference in p-CREB levels between Rab11CA-expressing neurons and control neurons was abolished (Fig. 9D,E). These results support the notion that the expression of constitutively active Rab11 enhances neuronal sensitivity to limiting levels of BDNF.

Finally, to address whether there is a functional relationship between Rab11 and Myosin Vb, we coexpressed the Rab11CA form and the MyoVbDN to assess whether MyoVbDN blocks the Rab11CA-induced dendritic branching. As shown in Figure 10, $2 \mathrm{~d}$ of expression of MyoVbDN in 7 DIV hippocampal neurons significantly reduced dendritic branching induced by the expression of Rab11CA.

\section{Discussion}

How BDNF and TrkB signaling orchestrate all of the cellular processes required to induce dendritic branching, such as intracellular trafficking and cytoskeleton rearrangement, is not well understood. The aim of our study was to determine whether Rab11-dependent trafficking of TrkB in dendrites regulates BDNFinduced dendritic branching. We show

\footnotetext{
$\leftarrow$

of dendritic branching in Rab11CA neurons was due to an increased response to endogenously secreted BDNF, we transduced neurons with adenovirus EGFP or Rab11CA and treated neurons with a blocking antibody against BDNF or the inhibitor K252a. The analysis of branching points showed that both anti-BDNF and K252a abolished the Rab11CA-induced increase of branching. The controls were treated with an unrelated chicken IgY antibody. $n=19-24$ neurons from three independent experiments. ${ }^{*} p<0.01$. $\boldsymbol{D}, \boldsymbol{E}$, To determine directly whether Rab11CA expression sensitized neurons to BDNF, we stimulated Rab11CA-neurons with $0,0.02,0.2$, or 2 nм BDNF and analyzed the nuclear translocation of pCREB transcription factor. Compared with EGFP, the Rab11CA neurons exhibited increased and significant responses to BDNF starting from $0.02 \mathrm{~nm}$. EGFP and Rab11CA are shown in green, pCREB in red, and Hoechst in blue (D). Quantification $(\boldsymbol{E})$ shows the BDNF-induced increase of nuclear PCREB over the baseline. $n=38-50$ neurons per treatment from two independent experiments. ${ }^{* *} p<0.01 ;{ }^{* * *} p<0.001$.
} 
that Rab11 activity is required for BDNFdependent dendritic branching by a mechanism in which $\operatorname{TrkB}$ activates the monomeric GTPase Rab11. We propose a model in which dendritic activation of Rab11 would increase recycling by promoting the interaction of Rab11 with Myosin $\mathrm{Vb}$, increasing the amount of Rab11-positive endosomes in secondary dendrites, a process that would require actin filaments. Because Rab11 endosomes carry TrkB, sustained Rab11 activity results in increased endogenous TrkB receptor levels in dendrites, implying that this mechanism potentiates TrkB signaling in dendrites (Fig. 11A). Therefore, this process provides a positive feedback mechanism to induce BDNF-dependent protrusion and the outgrowth of dendritic branches.

Rab11 GTPase has emerged as an important modulator of cellular transport by regulating the alternative association of recycling endosomes to actin-based or microtubule-based vesicular transport machineries (see below), allowing the delivery of cellular components or signaling molecules to specific locations in the cell (Jing and Prekeris, 2009). In this form, Rab11 regulates several cellular functions, such as asymmetric cell division and cytokinesis, phagocytosis, polarization, lateral membrane growth, axonal growth, and BDNF-induced dendritic branching (our work; (Cox et al., 2000; Lapierre et al., 2001; Pelissier et al., 2003; Riggs et al., 2007; Cao et al., 2008; Takano et al., 2010; Linford et al., 2012). Rab11 endosomes move using different molecular motors. When moving along microfilaments, the endosomes engage the actin-based Myo$\sin \mathrm{Vb}$ motor for short-distance vesicular movements (e.g., allowing the fusion of Rab11 vesicles with the plasma membrane; Lapierre et al., 2001). Rab11 also associates with the microtubule-based motors dynein and kinesin through different effectors, allowing Rab11 endosomes to move from the cell body to distal processes such as the axonal terminal, as shown in sympathetic neurons (Ng and Tang, 2008; Hirokawa et al., 2010; Takano et al., 2010). These results suggest that there is a switch mechanism between Rab11-associated motors for the control of vesicle transport. Indeed, this mechanism has been recently proposed for the recycling of Langerin (a c-type lectin receptor), in which the association of Rab11 endosomes with microtubule- and actin-based motors requires a sequential move from perinuclear endosomes to the plasma membrane (Gidon et al., 2012). Supporting a switch of Rab11 endosomes from microtubule to microfilament in dendrites, Rab11GDP can interact with protrudin, which serves as an adaptor to link Rab11-GDP to the microtubule-associated motor KIF5 (Matsuzaki et al., 2011). Therefore, it is possible that nonactive Rab11 endosomal trafficking is coupled to protrudin/KIF5 in microtubules but switches to
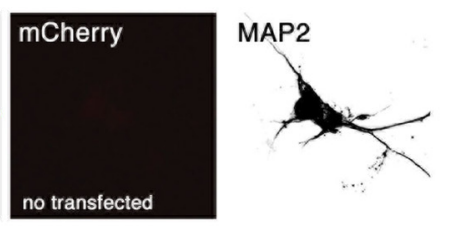

B

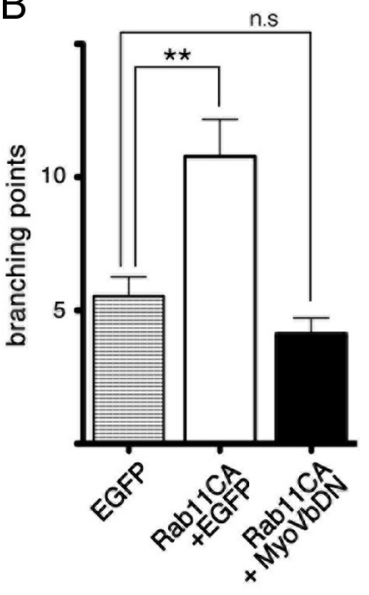

Figure 10. Expression of Myosin Vb dominant-negative blocks Rab11CA-induced dendritic branching. $\boldsymbol{A}$, Hippocampal neurons were cotransfected with Rab11CA-mCherry (red) and MyoVbDN-EGFP or EGFP (green) and stimulated with $4 \mathrm{~nm} \mathrm{BDNF} \mathrm{(100} \mathrm{ng/ml)}$ for $48 \mathrm{~h}$. Cotransfected neurons were also labeled with anti-MAP2 (black) for morphometric analysis. $\boldsymbol{B}$, The number of branching points showed that expression of MyoVbDN mutant abolished Rab11CA-induced increase of dendritic arborization significantly, showing a functional relationship between Rab11 GTPase and the actin-dependent motor protein Myosin Vb toward the ramifi-

A

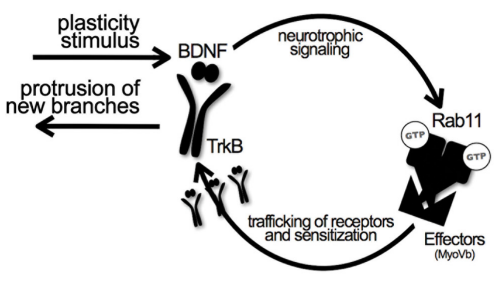
Rab11-dependent trafficking. It is known that different plastic stimuli are translated into an increase of available BDNF. BDNFinduced neurotrophic signaling increased the amount of the GTP-bound form of Rab11 that was available to interact with effectors to BDNF and promoting the protrusion of new branches in restricted localizations. $\boldsymbol{B}$, To interpret our results related to the mechanism of Rab11 endosome accumulation in dendrites after BDNF treatment, we can visualize the cell body and the dendriti 列 compartment. At steady state, equal numbers of Rab11-positive vesicles are entering and leaving the dendritic compartment at stationary. This process implies that fewer Rab11 vesicles leave the dendritic compartment than those that enter it. As a result, the number of Rab11 vesicles in the dendritic compartment increases rapidly.

microfilaments by interacting with Myosin $\mathrm{Vb}$ when Rab11 is in the GTP-bound form.

To our knowledge, our study provides the first evidence indicating that a signaling receptor regulates the activity and dynamics of Rab11-positive endosomes to induce a cellular response. We have modified a classic technique used to measure the activity of the monomeric GTPase RhoA in situ (Gehler et al., 2004), allowing us to detect the location of activated Rab11. This technique makes it possible not only to detect the total active monomeric GTPase in the cell (or the GTP-bound form), but also to identify the cellular compartment in which the activity is increased or decreased. Complementary live-cell imaging experiments indicated that BDNF rapidly increases the abundance of Rab11-positive endosomes in secondary dendrites. We observed 
that dendritic Rab11 endosome movements were bidirectional, exhibiting fusion and dispersion of packets and movements back and forth to and from the cell body. However, when BDNF was added to the culture media, the fluorescence associated with Rab11-EGFP in secondary dendrites increased significantly. In addition, these endosomes appeared to be less mobile and enlarged compared with the endosomes in the same dendrite before BDNF treatment. This is consistent with the fact that BDNFinduced enrichment of Rab11 endosomes in dendrites depends on actin filaments, which is a common feature of Rab11dependent recycling to the plasma membrane in different cell types (Lapierre et al., 2001; Fan et al., 2004; Nedvetsky et al., 2007). To explain our results, we propose a working model in which under basal conditions, Rab11 vesicles are moving inside the dendrites associated to microtubule-based motors. When BDNF activates TrkB signaling in dendrites, it promotes the interaction of Rab11 endosomes with Myosin Vb. In dendrites, this process would increase locally the recycling of TrkB to the plasma membrane. Finally, TrkB associated with Rab11 endosomes would stay in the dendritic recycling pathway rather than return to the cell body (Fig. 11B). This model is consistent with the increase of endogenous TrkB in dendrites when constitutively active Rab11 was expressed in hippocampal neurons and with the prominent recycling of TrkB in dendrites relative to the cell bodies.

Although we have provided the first evidence that BDNF regulates Rab11 endosomes, an intriguing question remains: how activated TrkB regulates the activity of Rab11. The biological function of the Rab GTPases depends on the association of their GTP-bound forms to effector proteins. Because Rabs have limited rate of GDP and GTP exchange, the interchange is promoted by guanine nucleotide exchange factors (GEFs). However, to date, no GEFs have been reported for the Rab11 family members Rab11a, Rab11b, and Rab25 (Linford et al., 2012). Huntingtin and LMTK1/AATYK1, two proteins that regulate the morphology of hippocampal neurons, have been reported to positively regulate the GDP/GTP exchange rate of Rab11; nevertheless, none of these proteins interacts directly with Rab11 (Li et al., 2008; Takano et al., 2010). A plausible explanation for the lack of promising Rab11-GEF candidates is that they are protein complexes. Indeed, it has been shown that TRAPPII is a protein complex that functions as GEF for the yeast Rab11 homolog Ypt31/ Ypt32 (Morozova et al., 2006). Extensive experimental work will be needed to establish the identity of Rab11-positive regulators in mammals. While this article was under review, a DENN family member with GEF activity for Rab11 in Drosophila was reported (Xiong et al., 2012).

Internalization is required for Akt activation and the regulation of neuronal morphology by BDNF in hippocampal neurons. It is possible that Rab11 dendritic endosomes are functionally equivalent to the apical endosomes of polarized cells, which could also serve as a platform for recruiting signaling molecules such as phosphoinositide-dependent kinase-1 (PDK1), the kinase that activates Akt and atypical protein kinase C (Zheng et al., 2008; Mashukova et al., 2012). The idea that the internalization and postendocytic trafficking of receptors is required to turn on specific signaling pathways has been proposed for several signaling receptors, including neurotrophin receptors (Bronfman et al., 2007; Sorkin and von Zastrow, 2009). In addition to the known function of receptor trafficking in signaling, our model offers a plausible mechanism to induce a transitory concentration of endosomes and signaling molecules in a particular location of the cell, in this case the dendrites of neurons, by increasing Rab11dependent recycling.

Another interesting implication of our findings is that BDNF might influence the transport of other Rab11 endosome cargos, including important regulators of neuronal physiology. Indeed, AMPA receptors and adhesion molecules such as $N$-cadherin are transported within dendritic Rab11 endosomes (Park et al., 2006; Wang et al., 2008; Kawauchi et al., 2010). Rab11-positive endosomes carrying AMPA receptors are found near the base of spines and filopodia, where they are sensitive to local signals that insert AMPA receptors into spines upon calcium influx (Kopec and Malinow, 2006; Park et al., 2006). The calcium sensor is Myosin $\mathrm{Vb}$, which is activated by calcium influx, increasing its association with Rab11 endosomes and triggering the insertion of AMPAR into the plasma membrane. TrkB also localizes to dendrites and regulates spine morphology and long-term potentiation (Santi et al., 2006; Minichiello, 2009; Yoshii and Constantine-Paton, 2010). Therefore, it is possible that TrkB signaling increases AMPA receptor localization in spines, thus increasing long-term potentiation through a mechanism that requires a TrkB-induced increase in Rab11 activity and association with Myosin Vb (Lisé et al., 2006; Wang et al., 2008).

Finally, BDNF signaling and Rab11 have been independently implicated in correcting pathological phenotypes in neurons and restoring structural plasticity in neurological disorders such as Huntington's disease (Ferrer et al., 1999; Lynch et al., 2007; Richards et al., 2011). Our results raise the possibility that the restorative effects of BDNF are mediated via a direct effect on regulating Rab11-GTPase activity.

\section{References}

Ascaño M, Richmond A, Borden P, Kuruvilla R (2009) Axonal targeting of Trk receptors via transcytosis regulates sensitivity to neurotrophin responses. J Neurosci 29:11674-11685. CrossRef Medline

Bolte S, Cordelieres FP (2006) A guided tour into subcellular colocalization analysis in light microscopy. J Microscopy 224:213-232. CrossRef

Bronfman FC, Escudero CA, Weis J, Kruttgen A (2007) Endosomal transport of neurotrophins: roles in signaling and neurodegenerative diseases. Dev Neurobiol 67:1183-1203. CrossRef Medline

Cao J, Albertson R, Riggs B, Field CM, Sullivan W (2008) Nuf, a Rab11 effector, maintains cytokinetic furrow integrity by promoting local actin polymerization. J Cell Biol 182:301-313. CrossRef Medline

Cheung ZH, Chin WH, Chen Y, Ng YP, Ip NY (2007) Cdk5 is involved in BDNF-stimulated dendritic growth in hippocampal neurons. PLoS Biol 5:e63. CrossRef Medline

Chu BB, Ge L, Xie C, Zhao Y, Miao HH, Wang J, Li BL, Song BL (2009) Requirement of myosin Vb.Rab11a.Rab11-FIP2 complex in cholesterolregulated translocation of NPC1L1 to the cell surface. J Biol Chem 284: 22481-22490. CrossRef Medline

Cox D, Lee DJ, Dale BM, Calafat J, Greenberg S (2000) A Rab11-containing rapidly recycling compartment in macrophages that promotes phagocytosis. Proc Natl Acad Sci U S A 97:680-685. CrossRef Medline

Fan GH, Lapierre LA, Goldenring JR, Sai J, Richmond A (2004) Rab11family interacting protein 2 and myosin $\mathrm{Vb}$ are required for CXCR2 recycling and receptor-mediated chemotaxis. Mol Biol Cell 15:2456-2469. CrossRef Medline

Ferrer I, Marín C, Rey MJ, Ribalta T, Goutan E, Blanco R, Tolosa E, Marti E (1999) BDNF and full-length and truncated TrkB expression in Alzheimer disease. Implications in therapeutic strategies. J Neuropathol Exp Neurol 58:729-739. CrossRef Medline

Gehler S, Gallo G, Veien E, Letourneau PC (2004) p75 neurotrophin receptor signaling regulates growth cone filopodial dynamics through modulating RhoA activity. J Neurosci 24:4363-4372. CrossRef Medline

Gidon A, Bardin S, Cinquin B, Boulanger J, Waharte F, Heliot L, de la Salle H, Hanau D, Kervrann C, Goud B, Salamero J (2012) A Rab11A/myosin $\mathrm{Vb} / \mathrm{Rab} 11-\mathrm{FIP} 2$ complex frames two late recycling steps of langerin from the ERC to the plasma membrane. Traffic 13:815-833. CrossRef Medline Goetze B, Grunewald B, Baldassa S, Kiebler M (2004) Chemically controlled 
formation of a DNA/calcium phosphate coprecipitate: application for transfection of mature hippocampal neurons. J Neurobiol 60:517-525. CrossRef Medline

Hales CM, Griner R, Hobdy-Henderson KC, Dorn MC, Hardy D, Kumar R, Navarre J, Chan EK, Lapierre LA, Goldenring JR (2001) Identification and characterization of a family of Rab11-interacting proteins. J Biol Chem 276:39067-39075. CrossRef Medline

Hales CM, Vaerman JP, Goldenring JR (2002) Rab11 family interacting protein 2 associates with Myosin $\mathrm{Vb}$ and regulates plasma membrane recycling. J Biol Chem 277:50415-50421. CrossRef Medline

Hirokawa N, Niwa S, Tanaka Y (2010) Molecular motors in neurons: transport mechanisms and roles in brain function, development, and disease. Neuron 68:610-638. CrossRef Medline

Horch HW, Katz LC (2002) BDNF release from single cells elicits local dendritic growth in nearby neurons. Nat Neurosci 5:1177-1184. CrossRef Medline

Jaworski J, Spangler S, Seeburg DP, Hoogenraad CC, Sheng M (2005) Control of dendritic arborization by the phosphoinositide-3'-kinase-Aktmammalian target of rapamycin pathway. J Neurosci 25:11300-11312. CrossRef Medline

Jing J, Prekeris R (2009) Polarized endocytic transport: the roles of Rab11 and Rab11-FIPs in regulating cell polarity. Histol Histopathol 24:1171-1180. Medline

Kawauchi T, Sekine K, Shikanai M, Chihama K, Tomita K, Kubo K, Nakajima K, Nabeshima Y, Hoshino M (2010) Rab GTPases-dependent endocytic pathways regulate neuronal migration and maturation through $N$-cadherin trafficking. Neuron 67:588-602. CrossRef Medline

Kennedy MJ, Ehlers MD (2006) Organelles and trafficking machinery for postsynaptic plasticity. Annu Rev Neurosci 29:325-362. CrossRef Medline

Kopec C, Malinow R (2006) Neuroscience. Matters of size. Science 314: 1554-1555. CrossRef Medline

Kumar V, Zhang MX, Swank MW, Kunz J, Wu GY (2005) Regulation of dendritic morphogenesis by Ras-PI3K-Akt-mTOR and Ras-MAPK signaling pathways. J Neurosci 25:11288-11299. CrossRef Medline

Lapierre LA, Kumar R, Hales CM, Navarre J, Bhartur SG, Burnette JO, Provance DW Jr, Mercer JA, Bähler M, Goldenring JR (2001) Myosin vb is associated with plasma membrane recycling systems. Mol Biol Cell 12:1843-1857. Medline

Li X, Sapp E, Valencia A, Kegel KB, Qin ZH, Alexander J, Masso N, Reeves P, Ritch JJ, Zeitlin S, Aronin N, Difiglia M (2008) A function of huntingtin in guanine nucleotide exchange on Rab11. Neuroreport 19:1643-1647. CrossRef Medline

Linford A, Yoshimura S, Nunes Bastos R, Langemeyer L, Gerondopoulos A, Rigden DJ, Barr FA (2012) Rab14 and its exchange factor FAM116 link endocytic recycling and adherens junction stability in migrating cells. Dev Cell 22:952-966. CrossRef Medline

Lisé MF, Wong TP, Trinh A, Hines RM, Liu L, Kang R, Hines DJ, Lu J, Goldenring JR, Wang YT, El-Husseini A (2006) Involvement of myosin $\mathrm{Vb}$ in glutamate receptor trafficking. J Biol Chem 281:3669-3678. CrossRef Medline

Lynch G, Kramar EA, Rex CS, Jia Y, Chappas D, Gall CM, Simmons DA (2007) Brain-derived neurotrophic factor restores synaptic plasticity in a knock-in mouse model of Huntington's disease. J Neurosci 27:4424-4434. CrossRef Medline

Mashukova A, Forteza R, Wald FA, Salas PJ (2012) PDK1 in apical signaling endosomes participates in the rescue of the polarity complex atypical PKC by intermediate filaments in intestinal epithelia. Mol Biol Cell 23:1664-1674. CrossRef Medline

Matsuzaki F, Shirane M, Matsumoto M, Nakayama KI (2011) Protrudin serves as an adaptor molecule that connects KIF5 and its cargoes in vesicular transport during process formation. Mol Biol Cell 22:4602-4620. CrossRef Medline

Maxfield FR, McGraw TE (2004) Endocytic recycling. Nat Rev Mol Cell Biol 5:121-132. CrossRef Medline

Meyers JM, Prekeris R (2002) Formation of mutually exclusive Rab11 complexes with members of the family of Rab11-interacting proteins regulates Rab11 endocytic targeting and function. J Biol Chem 277:49003-49010. CrossRef Medline

Minichiello L (2009) TrkB signalling pathways in LTP and learning. Nat Rev Neurosci 10:850-860. CrossRef Medline

Morozova N, Liang Y, Tokarev AA, Chen SH, Cox R, Andrejic J, Lipatova Z,
Sciorra VA, Emr SD, Segev N (2006) TRAPPII subunits are required for the specificity switch of a Ypt-Rab GEF. Nat Cell Biol 8:1263-1269. CrossRef Medline

Nedvetsky PI, Stefan E, Frische S, Santamaria K, Wiesner B, Valenti G, Hammer JA 3rd, Nielsen S, Goldenring JR, Rosenthal W, Klussmann E (2007) A Role of myosin $\mathrm{Vb}$ and Rab11-FIP2 in the aquaporin-2 shuttle. Traffic 8:110-123. CrossRef Medline

Ng EL, Tang BL (2008) Rab GTPases and their roles in brain neurons and glia. Brain Res Rev 58:236-246. CrossRef Medline

Park M, Salgado JM, Ostroff L, Helton TD, Robinson CG, Harris KM, Ehlers MD (2006) Plasticity-induced growth of dendritic spines by exocytic trafficking from recycling endosomes. Neuron 52:817-830. CrossRef Medline

Pelissier A, Chauvin JP, Lecuit T (2003) Trafficking through Rab11 endosomes is required for cellularization during Drosophila embryogenesis. Curr Biol 13:1848-1857. CrossRef Medline

Richards P, Didszun C, Campesan S, Simpson A, Horley B, Young KW, Glynn P, Cain K, Kyriacou CP, Giorgini F, Nicotera P (2011) Dendritic spine loss and neurodegeneration is rescued by Rab11 in models of Huntington's disease. Cell Death Differ 18:191-200. CrossRef Medline

Riggs B, Fasulo B, Royou A, Mische S, Cao J, Hays TS, Sullivan W (2007) The concentration of Nuf, a Rab11 effector, at the microtubuleorganizing center is cell cycle regulated, dynein-dependent, and coincides with furrow formation. Mol Biol Cell 18:3313-3322. CrossRef Medline

Santi S, Cappello S, Riccio M, Bergami M, Aicardi G, Schenk U, Matteoli M, Canossa M (2006) Hippocampal neurons recycle BDNF for activitydependent secretion and LTP maintenance. EMBO J 25:4372-4380. CrossRef Medline

Saraste J, Goud B (2007) Functional symmetry of endomembranes. Mol Biol Cell 18:1430-1436. CrossRef Medline

Satoh D, Sato D, Tsuyama T, Saito M, Ohkura H, Rolls MM, Ishikawa F, Uemura T (2008) Spatial control of branching within dendritic arbors by dynein-dependent transport of Rab5-endosomes. Nat Cell Biol 10: 1164-1171. CrossRef Medline

Shimada A, Mason CA, Morrison ME (1998) TrkB signaling modulates spine density and morphology independent of dendrite structure in cultured neonatal Purkinje cells. J Neurosci 18:8559-8570. Medline

Sholl DA (1953) Dendritic organization in the neurons of the visual and motor cortices of the cat. J Anat 87:387-406. Medline

Sorkin A, von Zastrow M (2009) Endocytosis and signalling: intertwining molecular networks. Nat Rev Mol Cell Biol 10:609-622. CrossRef Medline

Takano T, Tsutsumi K, Saito T, Asada A, Tomomura M, Fukuda M, Hisanaga S (2010) AATYK1A phosphorylation by Cdk5 regulates the recycling endosome pathway. Genes to cells: devoted to molecular and cellular mechanisms 15:783-797. CrossRef

Takemoto-Kimura S, Ageta-Ishihara N, Nonaka M, Adachi-Morishima A, Mano T, Okamura M, Fujii H, Fuse T, Hoshino M, Suzuki S, Kojima M, Mishina M, Okuno H, Bito H (2007) Regulation of dendritogenesis via a lipid-raft-associated $\mathrm{Ca}^{2+} /$ calmodulin-dependent protein kinase CLICK-III/CaMKIgamma. Neuron 54:755-770. CrossRef Medline

Ullrich O, Reinsch S, Urbé S, Zerial M, Parton RG (1996) Rab11 regulates recycling through the pericentriolar recycling endosome. J Cell Biol 135: 913-924. CrossRef Medline

Wang Z, Edwards JG, Riley N, Provance DW Jr, Karcher R, Li XD, Davison IG, Ikebe M, Mercer JA, Kauer JA, Ehlers MD (2008) Myosin Vb mobilizes recycling endosomes and AMPA receptors for postsynaptic plasticity. Cell 135:535-548. CrossRef Medline

Watson A, Latchman D (1996) Gene delivery into neuronal cells by calcium phosphate-mediated transfection. Methods 10:289-291. CrossRef Medline

Xiong B, Bayat V, Jaiswal M, Zhang K, Sandoval H, Charng WL, Li T, David G, Duraine L, Lin YQ, Neely GG, Yamamoto S, Bellen HJ (2012) Crag Is a GEF for Rab11 required for rhodopsin trafficking and maintenance of adult photoreceptor cells. PLoS Biol 10:e1001438. CrossRef Medline

Xu B, Zang K, Ruff NL, Zhang YA, McConnell SK, Stryker MP, Reichardt LF (2000) Cortical degeneration in the absence of neurotrophin signaling: dendritic retraction and neuronal loss after removal of the receptor TrkB. Neuron 26:233-245. CrossRef Medline

Yan Q, Radeke MJ, Matheson CR, Talvenheimo J, Welcher AA, Feinstein SC 
(1997) Immunocytochemical localization of TrkB in the central nervous system of the adult rat. J Comp Neurol 378:135-157. CrossRef Medline

Yang WK, Peng YH, Li H, Lin HC, Lin YC, Lai TT, Suo H, Wang CH, Lin WH, Ou CY, Zhou X, Pi H, Chang HC, Chien CT (2011) Nak regulates localization of clathrin sites in higher-order dendrites to promote local dendrite growth. Neuron 72:285-299. CrossRef Medline

Ye B, Zhang Y, Song W, Younger SH, Jan LY, Jan YN (2007) Growing dendrites and axons differ in their reliance on the secretory pathway. Cell 130:717-729. CrossRef Medline
Yoshii A, Constantine-Paton M (2010) Postsynaptic BDNF-TrkB signaling in synapse maturation, plasticity, and disease. Dev Neurobiol 70: 304-322. CrossRef Medline

Zheng J, Shen WH, Lu TJ, Zhou Y, Chen Q, Wang Z, Xiang T, Zhu YC, Zhang C, Duan S, Xiong ZQ (2008) Clathrin-dependent endocytosis is required for TrkB-dependent Akt-mediated neuronal protection and dendritic growth. J Biol Chem 283:13280-13288. CrossRef Medline 